\title{
MULHERES QUE NARRAM: UMA ANÁLISE DAS PUBLICAÇÕES DA ESCOLA BRASILEIRA DE ADMINISTRAÇÃO PÚBLICA EM SEU PERÍODO DE IMPLANTAÇÃO - 1954 A 1977
}

\author{
WOMEN WHO NARRATE: AN ANALYSIS OF THE PUBLICATIONS OF THE \\ BRAZILIAN SCHOOL OF PUBLIC ADMINISTRATION IN ITS IMPLEMENTATION \\ PERIOD - 1954 TO 1977.
}

Laura Henrique Corrêa

Universidade de São Paulo, SP, Brasil

E-mail:correalaura@hotmail.com

Aline Lourenço de Oliveira

Universidade Federal de Alfenas, MG, Brasil E-mail: alinelourenco@unifalmg.edu.br

Recebido em: 10.05.2020 - Aceito em: 27.10.2020

DOI: http://dx.doi.org/10.5902/2526629244191

RESUMO: O objetivo deste estudo foi compreender como as narrativas femininas integraram o período de surgimento e de implantação dos cursos de Administração Pública no Brasil, partindo da análise das publicações da Escola Brasileira de Administração Pública (EBAP) no período de 1954 a 1977. Para isso, foram analisadas todas as publicações e evidenciados os fragmentos das narrativas femininas, explorando suas características e contribuições. Esse percurso apresentou como resultado a descrição de abordagens e de interesses diferenciados da ótica masculina: sensibilidade social, artes nas diversas formas, maneiras de transmitir conhecimentos, espaços de lazer, entre outros, que se mostraram mais próximos da produção de saberes locais do que da importação de saberes característica do período. Tais manifestações, por um lado, evidenciam os efeitos de práticas educativas menos difundidas, demonstrando que não é novidade a elaboração de saberes mais plurais e mais próximos da cotidianidade. Já por outro, incitam à efetividade da remontagem histórica para recuperar existências que nem sempre serviram aos desígnios predominantes em uma época.

Palavras Chave: Narrativas femininas; Administração Pública; Historiografia. EBAP.

ABSTRACT: The objective of this study was to understand how female narratives integrated the period of emergence and implementation of Public Administration courses in Brazil, based on the analysis of publications from the Brazilian School of Public Administration (EBAP) in the period from 1954 to 1977. All publi- 
cations were analyzed and fragments of female narratives were highlighted, exploring their characteristics and contributions. This path resulted in the description of different approaches and interests from the male perspective: social sensitivity, arts in different forms, ways of transmitting knowledge, leisure spaces; among others, which were closer to the production of local knowledge than to the import of knowledge - characteristic of the period. Such manifestations, on the one hand, show the effects of less widespread educational practices; and, yet, they demonstrate that the elaboration of the most plural knowledge and closer to everyday life is not new. On the other hand, they encourage the effectiveness of historical reassembly to recover existences that did not always serve the purposes that prevailed at a time.

Keywords: Female narratives; Public administration; Historiography. EBAP.

\section{INTRODUÇÃO}

Efetivar o destaque da narrativa feminina ao longo de um processo histórico não é uma atividade recente e, muito menos, que se apresenta como restauradora da presença dos corpos femininos no tempo-espaço. A exploração, assim, se dá de maneira mais módica, primando pela dignidade científica de não narrar por existências e, nem mesmo, utilizá-las como objeto de comprovação de uma ou de outra teoria.

Apenas apresentar algumas das vozes que compõe o emaranhado de discursos circunscritos em um arquivo. Esse pode ser o objetivo geral que permeia todo esse escrito, resultado de muitas horas de perscruta atenta e pautada no que já inferira Paul Ricoeur (2014): não se evidencia o passado, se reconfigura, pois, articular o passado é como um cintilar, num instante de perigo. Uma ameaça provocante, que, no uso do olhar crítico, ao diagnosticar a infâmia de uns, logo se debruça nas elevações de suas práticas e seus modos de existir.

A apresentação do diverso que incomoda, como explica o professor e historiador Durval Muniz de Albuquerque Júnior (2018) ao falar sobre as habituais inserções masculinas dos discursos no contexto brasileiro, mostra que a sociedade "falocêntrica" não se furtou a oferecer seu vasto cardápio nos mais diferentes campos de experiência dos corpos. Isso, na implantação da escola de Administração Pública no Brasil, também não parece ter se mostrado díspar.

Para sustentar tal argumentação, duas lacunas são prementes. A primeira se refere aos estudos históricos em geral, que segundo Coelho $(2019$, p.14) exceto na tese de doutorado de Fischer (1984) e, tangencialmente, em artigos e 
relatórios de pesquisa de Mezzomo Keinert (1994; 1996), "não se estudou a educação superior em Administração Pública no Brasil, pormenorizadamente, como história". Já a segunda, vai ao encontro de um abismo ainda maior: a presença feminina na constituição desse saber, em suas particularidades e diferenças.

$\mathrm{Na}$ área de Administração Pública, em sua prática ou em seu ensino, o enfoque feminino não é o mais evidenciado tanto na linha histórica de progresso, frequentemente utilizada, quanto nas vozes mais propagadas nas publicações. Nesse ponto, elevar tais expressões se mostra como potência de uma história considerada menos unificante e mais próxima das forças que compõem um acontecimento; ou, nas palavras de Foucault (2014, p. 212), "outro poder, outro saber", que impulsiona a história a deslocar, ainda que minimamente, da repetição pura. Ao se alocar mais próxima da observação de suas tramas, no tecer de seus conflitos, saberes concorrentes e poderes, explana-se o espaço no qual os acontecimentos são elementos da estratégia aqui observadas por uma das vias possíveis: a feminina.

Em uma área considerada por muitos enrijecida e predominantemente masculina, explorar como foi delineada a participação feminina, justamente no período em que se iniciou essa formação no Brasil e destacar as narrativas expressas nos periódicos da escola em implantação, pode evidenciar formações históricas que apresentam efeitos em tempos hodiernos. Portanto, ao operar neste recorte que marca a visibilidade das agentes e de seus escritos no momento da constituição da primeira escola de Administração Pública no Brasil, além de destacar as especificidades desta narrativa, se abre espaço para o delineamento da emergência feminina por seus próprios registros, e, principalmente, se movimenta o funcionamento dessa narrativa com sua prática desempenhada.

Devido a este contexto, o estudo que ora se apresenta, explorou brevemente as narrativas femininas com suas características e contribuições no processo de implantação do ensino de Administração Pública no Brasil, por meio da análise dos registros da EBAP, publicados no período de 1954 a 1977, ou seja, em todo período de produção dos cadernos de Administração Pública.

Mapeando esse movimento de deslocamento por meio da remontagem histórica dentro das informações que circularam nos periódicos, evidencia-se um fragmento do passado em narrativas menos hegemônicas. Com tal procedimento, espera-se acompanhar e constituir novas tessituras possíveis - sem qualquer gênero dominante -, em experiências para a formação dos administradores públicos durante seu percurso educacional, abrindo espaço para estranhamentos e novas linhas exploráveis no campo da formação administrativa. 


\section{METODOLOGIA}

Aproximando-se do entendimento do historiador Paul Veyne (2018, p. 8), para o qual "a história não explica e não tem método", aqui se dispõe a historiar apenas narrando acontecimentos. Entretanto, foi efetivado um percurso para que fosse possível apresentar os resultados da análise em uma narrativa histórica que efetiva sua composição por meio das existências ali elencadas, com seus recortes e suas pequenas sobrevivências. Assim, para mapear a existência desses discursos que compõem o saber público-administrativo em seu cunho histórico, foram utilizados os cadernos de Administração Pública produzidos pela primeira escola brasileira de administração pública (EBAP), no período de implantação desse saber institucional no Brasil.

Segundo Coelho (2019, p.45), esse periódico foi a catalogação de "um acervo considerado basilar e com a publicação (incluindo a tradução de manuais), de revistas e relatórios de investigações". São compostos por uma sequência de 104 (cento e quatro) publicações produzidas por 60 (sessenta) autores, que ocorreram atravessando três décadas, entre os anos de 1954 a 1977, e que constituem campo privilegiado de discursos dos acontecimentos no país nessas épocas. Segundo Coelho (2019, p. 45), "esse foi o primeiro material didático conformado para o ensino de administração pública no Brasil”. A escolha desse periódico se deu pela sua produção ser interna, exatamente elaborada pelos que envidavam seus esforços na implantação do saber administrativo no Brasil, explanando rastros de suas influências, de suas práticas e de suas preferências dentro dos saberes e dos poderes concorrentes que acompanham a implementação da instituição educativa.

Nesse entendimento, o primeiro levantamento realizado foi a quantidade de publicações por autor(a). Nesse compilado, foi possível observar a predominância de autores masculinos com 50 (cinquenta) expressões, tendo apenas 10 (dez) escritos femininos em um total de 60 (sessenta) autores entre os anos de 1954 a 1977, período em que houve a produção do periódico como resposta à necessidade de produção de material didático para um saber que estava se delineando em solo brasileiro.

Já constatado um maior número de autores, a quantidade de publicação separada por gêneros também foi analisada como um fator que expressa os discursos da época. No quantitativo total de publicações, o discurso circulado nos periódicos é composto em mais de $80 \%$ (oitenta percentuais) pela narrativa masculina, evidenciando uma forte tendência à ratificação dos saberes produzidos sob a ótica masculina. 
Dada essa constatação, da voz masculina comparecer predominantemente, aqui, se optou por evidenciar tão somente as narrativas femininas; se limitando a fazer apenas um comentário inicial do contexto e das temáticas masculinas em questão. Esse direcionamento se deu, condizendo com o objetivo de explorar todas as vozes femininas durante essas três décadas, com suas particularidades, sem o objetivo de produzir comparações, mas sim, de criar um nível maior de circulação.

\section{A NARRATIVA FEMININA NA EXPERIÊNCIA BRASILEIRA DE FORMALIZA- ÇÃO DOS SABERES EM ADMINISTRAÇÃO PÚBLICA}

\subsection{Contextualização inicial}

O primeiro importante destaque é que o discurso predominante na época respondia ao período histórico: década de 1950, com sua política desenvolvimentista, seu aumento da população urbana e sua expansão das indústrias e das instituições escolares. Nesse momento, se considerava importante adequar um sistema de ensino às necessidades criadas, e, portanto, ocorria a valorização dos saberes produzidos com temáticas que respondessem a esse problema.

Um primeiro ponto interessante a se observar é que a predominância das temáticas femininas segue tangencialmente à preocupação marcada pelo discurso desenvolvimentista, ainda que essa ocorra dentro do espaço e da pauta educativa em que se compunha o cenário. Nos tópicos elencados a seguir, será possível observar os fragmentos selecionados de cada autora com suas características.

\subsection{As Vozes femininas presentes}

Constam nos cadernos de administração pública da Escola Brasileira de Administração Pública (EBAP) as vozes de: Maria Ângela Vinagre de Almeida; Riva Bauzer; Ana Maria Brasileiro; Maria Pia Duarte Gomes; Marina Brandão Machado; Ethel Bauzer Medeiros; Fela Moscovici; Ruth Scheeffer; Catheryn Seckler-Hudson; e Beatriz M. de Souza Wahrlich.

\subsubsection{Maria Ângela Vinagre de Almeida: a didática participativa}

Autora de "Instrução Programada: teoria e prática" (1970), Maria Ângela Vinagre de Almeida se dedicou, nessa publicação, a pesquisar os efeitos da instru- 
ção programada, um sistema de treinamento e de disseminação de informações que na época se espalhava pelo mundo, uma inovação para os sistemas de ensino no período. Sua pesquisa foi dividida em três partes: teoria, aplicação e avaliação. Desta maneira, explorou, na primeira parte, os antecedentes históricos, as características do método e as pesquisas em outros países; na segunda parte, a experiência brasileira de aplicação e de suas críticas; e na terceira parte, suas conclusões diante dos problemas fundamentais encontrados.

Ainda que dentro de um panorama que afirmava a possibilidade de máquinas programadas de ensino, na qual professor e educando teriam um caminho de instrução predeterminada a seguir, a concepção de educação a ser elaborada estabelecia a participação ativa dos educandos brasileiros, seus interesses e suas personalidades e diferenças. Esses são aspectos explanados com frequência em sua narrativa, como é possível observar:

[...] no panorama geral da educação contemporânea, a nova metodologia retoma e reforça algumas das posições assumidas pelos representantes da Escola Nova que, por sua vez, enalteceram princípios já formulados por seus antecessores, tais como: atividade do aluno, motivação apropriada, reforço adequado, reconhecimento das diferenças individuais, respeito à personalidade do educando, etc. (Almeida, 1970, p. 5).

Suas concepções metodológicas de participação e de atenção aos educandos, além da teoria expressa, é demonstrada na própria pesquisa, como é possível constatar em seus agradecimentos, o posicionamento de elaboração da pesquisa junto aos educandos que colaboraram e produziram:

[...] ao bacharel em Administração Pública, Luís Severino Macêdo de Oliveira, então aluno do $4^{\circ}$ ano da EBAP, que, na função de auxiliar de pesquisa, aplicou a maioria dos questionários, realizou quase todas as entrevistas e inclusive é responsável pela segunda parte desta monografia (Almeida, 1970, p. 8).

Nesse agradecimento, a atividade do educando é salientada, sua atuação tanto na coleta de dados experimentais quanto na elaboração teórica do periódico em questão. Isso demonstra o quanto Almeida é enfática na "exigência de participação ativa do aluno durante todo o decorrer do processo de aprendizagem" (Almeida,1970, p. 33), explicitando também a contrapartida necessária do educando ao afirmar que "tão-somente o interesse é capaz de determinar atividades que sistematizem a conduta, proveitosamente, tanto na criança quanto no adulto" (Almeida, 1970, p. 50-51).

Nessa exigência educativa de motivação e de respeito ao aluno de um lado, e de interesse e de atividade de outro, Almeida parece diagnosticar que em al- 
guma parte o elo educativo se perde. Isso a faz apresentar uma advertência ao modelo de ensino utilizado, aliando os dados colhidos sobre evasão e avaliação:

Fizemos referência ao fenômeno dos estudantes desistentes, que simplesmente abandonam a escola: esta situação vai piorar muito mais, devido à frustração dos estudantes em relação à sua participação no processo de ensino (Almeida, 1970, p. 58).

Quando nota o quantitativo elevado de desistentes como um fator de distanciamento entre a interação no ambiente escolar, seja entre os pares ou entre os conteúdos apresentados, a frustração é um elemento presente e que, segundo a autora, tende a elevar os índices de desistência. Esse elemento foi esclarecido pela autora nas investigações experimentais que "demonstraram, realmente, que um número muito grande de fracassos (isto é, de punições implícitas) desanima o aluno" (Almeida, 1970, p.58).

Após todos esses caminhos percorridos, conclui que a Instrução Programada deve ser empregada como método didático em diversas áreas do ensino de Administração, não tanto como método único de instrução, mas associado a uma variedade de técnicas de ensino que sejam complementares. Essa elaboração de um modelo possível para a instrução se mostra uma das tentativas de minimizar os dados experimentais alarmantes que a pesquisadora encontra quando analisa o binômio avaliação e evasão, na educação em Administração Pública.

\subsubsection{Ana Maria Brasileiro: o processo de escuta na pesquisa}

Autora de "O assessoramento legislativo" (1968), Ana Maria Brasileiro se dedicou nessa publicação a pensar o assessoramento legislativo enquanto teoria, e também fez uma análise institucional prática do senado, da câmara dos deputados e das assembleias legislativas brasileiras.

Priorizou, como metodologia, o processo de escuta pela via das entrevistas, com abertura de fala, como descreve:

As entrevistas foram orientadas por um roteiro de perguntas abertas, isto é, que possibilitavam ao entrevistado manifestar-se livremente dentro do assunto indagado. Tal procedimento, embora dificulte a tabulação e interpretação dos dados, trazendo às vezes como consequência um abrandamento do rigor científico, permite, em contraposição, a descoberta de fatos novos com que o pesquisador antes não contara (Brasileiro, 1968, p.15). 
Nesse fragmento é possível perceber que a pesquisadora, ainda que pondere as críticas ao método científico com maior abertura, opta por este, inferindo que o benefício de novas informações à pesquisa justificam a maior dificuldade metodológica, sendo a primeira o ponto principal de toda atividade investigativa, visualizar, questionar e explorar novos fatos, pois a pesquisa exploratória, para Brasileiro (1968, p.16), "não se propõe a descobrir relações de causa e efeito mas sim, a fornecer informações úteis sobre a realidade e sugerir hipóteses para posteriores investigações".

Dessa maneira, o arcabouço de pesquisa montado por Brasileiro (1968) é todo embasado no processo de escuta, no qual, ouvidos os entrevistados, se fazia uma descrição para melhor delineamento dos fatos. Nesse processo também incorporou as sugestões dos entrevistados, apresentando-as. Em seu estudo, o processo de escuta é o elemento central da pesquisa que levou a categorização das informações, juntando-as para que fosse possível estabelecer uma linha de racionalidade da experiência vivenciada pelos entrevistados, em cada órgão abordado. A análise feita pela pesquisadora procurou ser sempre no sentido de levantar hipótese, de fazer indagações e observações que ajudassem a esclarecer os fatos, pois, para Brasileiro (1968, p.16), "a interpretação desses dados teve um cunho bastante descritivo e visava a colocar o leitor em posição de julgar por ele mesmo".

Condizendo com tal postura, ao final estabeleceu uma conclusão para cada espaço de atuação, após a constatação de que as necessidades variaram muito em cada espaço pesquisado, com suas características específicas. Concluiu, levantando hipóteses, que enfatiza ser a necessidade de pesquisas mais aprofundadas em cada órgão.

\subsubsection{Maria Pia Duarte Gomes: modelos de reflexão conjunta}

Autora de "Processo Decisório" (1968), Maria Pia Duarte Gomes realizou o registro de treze seminários sobre a temática de processos decisórios junto a professores e educandos. Gomes inicia seu escrito com esta citação de Highet sobre "A arte de ensinar":

Qualquer coisa que mereça ser ensinada leva tempo - tempo para ensinar, tempo para aprender. A monotonia no ensino é um grave defeito. E é um defeito grave porque o mundo muda, e a educação deve mudar com ele; ademais, o professor muda também e isso deve fazer variar o ensino (Highet apud Gomes, 1965, p. 9). 
Concordando com a prática educativa em um movimento contínuo, Gomes (1965, p. 11) valoriza a experiência, afirmando logo de início: "Esta monografia relata a experiência feita" e vai delineando seus procedimentos. Com um sucinto recorte histórico, expõe seus objetivos e sua metodologia, entretanto, a maior parte da pesquisa se dá nos próprios seminários que abordaram estudos de casos específicos e o pensamento de soluções em grupos de até quinze educandos. O mesmo ocorre quando aponta brevemente seu objetivo: "É este, em resumo, o plano do trabalho que pretende ser, apenas, um ponto de partida para a realização de outras experiências que renovem o ensino da administração" (Gomes, 1965, p. 12).

Em cada seminário, uma ação diferente era adotada. Cada membro com sua tarefa diante de um caso apresentado elaborava suas reflexões e suas hipóteses e discutia com o grupo, que envolvia educadores e educandos para uma situação específica pois, segundo Gomes (1965, p.13), "O objetivo básico era o de proporcionar oportunidade para o debate de ideias sobre a tomada de decisões". Neste contexto, situações inesperadas e pensamentos em teste eram os objetivos da experiência, pois, segundo a autora, "todos os esforços se dirigiriam no sentido de caracterizar o processo decisório como um comportamento sujeito a mudanças constantes. Por isso mesmo, seria impossível fixar regras de conduta" (Gomes, 1965, p.14).

A regra, então, seria a elaboração da experiência conjunta para obter modelos reflexivos, como esclarece:

No entanto, por se tratar de uma experiência original que lançaria mão de processos didáticos novos, procurar-se-ia, também, despertar nos estudantes o gosto pela indagação intelectual e o interesse pela aplicação de modernas técnicas de treinamento. Seria, realmente, uma tentativa de transformar o "aluno" em "estudante" (Gomes, 1965, p.13).

Fica evidente a valorização que a pesquisadora expressa sobre o questionamento reflexivo para a formação do educando da EBAP, trazendo ao estudante a perspectiva de sua atuação ampla, desvencilhando a ação do administrador do útil fazedor de tarefas, ou mesmo cumpridor de determinações, pois a experiência:

[...] permitiria que os fossem levados a meditar sobre o comportamento administrativo e governamental, de modo a entender que a administração não é uma atividade mecânica, mas está relacionada, de maneira profunda, com o total e complexo processo social e político (Gomes, 1965, p.14).

Essa implicação do administrador que não atua de maneira mecânica perpassa a formação do estudante, chegando à ação do professor, indicada também como movente e reflexiva. Assim, no modelo de reflexão conjunta, há valoriza- 
ção da experiência, não apenas no viés do educando, mas também do educador, como é possível notar neste fragmento de expressão:

[...] muitas vezes o professor inicia um curso como este com certo temor pela inovação, com aquele receio natural que se sente ao enfrentar uma situação nova, mas o entusiasmo dos alunos, diante dos primeiros êxitos, os resultados positivos, o ambiente cordial que se torna e, porque não dizer, até as dificuldades enfrentadas e vencidas transformam-se em compensações pelo esforço despendido e em estímulo para outras experiências (Gomes, 1965, p.106).

Os temores do movimento educativo e a imprevisibilidade do modelo apresentado são expostos tanto por dificuldades, aos que iniciam e se adaptam ao pensamento e a seus abalos fugindo um pouco da esperada monotonia educativa, como causa do êxito e da sua multiplicação. Ao final, a autora conclui que, apesar de todas as dificuldades elencadas, a inserção da experiência prática de colocar professores e educandos em inesperadas situações que necessitavam de uma decisão foi satisfatória, bem como a reflexão em conjunto destas, enfatizando que a melhor técnica didática é a aplicação de várias técnicas.

\subsubsection{Marina Brandão Machado: saberes na prática de estágio}

Autora de "Estágios de treinamento para estudantes de administração: a experiência da EBAP" (1970), Marina Brandão Machado registrou a experiências de educandos da escola brasileira de Administração Pública em seus períodos de estágio. Esse espaço de contato orientado com o exterior da EBAP foi motivo de questionamento pela pesquisadora:

[...] ressentem-se os alunos da falta de prática. Os cursos são muito teóricos, queixam-se eles, e com razão. Mestres e educadores há que não vêem mal nisto, opinando que a prática terá de vir mesmo após a diplomação. Mas, por que não fazer do ensino em geral uma atividade teórica e a um só tempo prática? Não será esse o autêntico tirocínio profissional, a pedagogia verdadeira? Efetivamente, só se aprende vendo, fazendo, entretanto em estreito contato com a realidade. $O$ aprendizado, quando bem exercido, torna-se não um preparo para a vida, senão a própria vida (Brandão, 1970, p.17).

Na reflexão da autora, o contato com o cotidiano da profissão era um fator formativo importante, que fazia o elo com a parte teórica apresentada no curso, formando não apenas o profissional para atuar em órgãos da administração pública, mas o administrador público que, já provido de experiências reflexivas, orien- 
tadas, estaria mais hábil para a atuação após a diplomação. Essa perspectiva não demonstrava um julgamento valorativo, de uma ou de outra postura, mas sim que a valoração da experiência teórica deveria ser equitativa à prática, uma estrada de mão dupla. Nesse ponto, a pesquisadora também enfatiza o processo reflexivo no ensino superior:

A principal função do ensino superior não é ensinar a fazer coisas de forma fácil e imediata, mas a de informar o aluno sobre ideias e categorias fundamentais de cada disciplina, e exercitar a sua inteligência para formular ideias e soluções com autonomia de pensamento (Brandão, 1970, p.1).

Para chegar a essa postura de unificação das vias em equidade, Brandão (1970) necessitou ouvir educandos, ex-alunos e professores, sintetizando as informações em gráficos e tabelas, apontando para a contribuição dos próprios estudantes na construção de suas análises, como é possível ver em sua expressão:

De grande relevância para o presente trabalho era conhecer a opinião dos alunos sobre o valor dos estágios realizados. E, mais uma vez, as críticas constantemente ouvidas foram negadas pelo resultado da investigação [...] Nele se comprova que a maior percentagem das opiniões $(48,7 \%)$ classificou a aprendizagem efetuada como capaz de dar uma visão de conjunto dos problemas técnicos, aspecto altamente positivo (Brandão, 1970, p.42).

A pesquisadora parece exprimir que a visão do conjunto das relações educativas se faz necessária para a compreensão da atuação profissional como um todo, fazendo com que explane os objetivos e as utilidades dos estágios, juntamente com a avaliação positiva da prática em campo, predominante entre os participantes, demonstrando que "o estágio é uma motivação para o estudo teórico" (Brandão, 1970, p.119).

\subsubsection{Ethel Bauzer Medeiros: arte e lazer para o planejamento social}

Marcando desde as primeiras palavras seu estilo um pouco diferenciado, Medeiros começa sua publicação com a citação de William Henry Davie, para justificar a importância do lazer na vida das pessoas, inferindo a relevância da temática para a educação em Administração Pública:

De que vale a tua vida, se, em meio à lida, não achas tempo para te deteres e te pores a contemplar. Tempo de sob a ramada te deitares e, como as vacas e as ovelhas, longas horas ficares a fitar. Tempo para à luz do dia poderes enxergar rios cheios de 
estrelas, como um céu a cintilar. Tempo de teus olhos volveres para uma beleza a despontar e apreciares como há pés que sabem dançar. Tempo de esperares uma boca terminar o riso que uns olhos começaram a esboçar. Afinal, que pobre vida é essa tua, se, sempre em meio à lida, não achas tempo para te deteres e te pores a contemplar.

(Davie apud Medeiros, 1971, p.1).

A autora de "O lazer no planejamento urbano" (1971;1975) explorou a temática do lazer na sociedade pós-industrial, que, segundo ela, é marcada pela vida pobre em aspectos artísticos, ancorando assim sua defesa à valorização do lazer junto ao meio público como uma questão não apenas pessoal, mas coletiva. Cita Euclides da Cunha em "Os Sertões" como exemplo da simplicidade do canto em rimas como lazer partilhado desde as mais tênues condições:

Um cabra destalado ralha na viola. Serenam, em vagorosos meneios, as caboclas. Nos intervalos travam-se os desafios... entre dois cantores rudes. As rimas saltam e casam-se em quadras muita vez belíssimas (Cunha apud Medeiros, 1975, p.43).

Partindo da necessidade latente dos viventes com suas quadras desafiadoras e belas, Medeiros elabora bases e diretrizes para um projeto de espaço de lazer. Suas narrativas $(1971 ; 1975)$ se apoiam inicialmente na perspectiva filosófica, retornando aos Gregos e posteriormente aos Romanos, demonstrando por diferentes perspectivas e organizações, da pólis ao império, que o lazer sempre esteve ligado à necessidade de ócio, sendo esse essencial à vida em diversas modalidades e expressões artísticas.

Sem o gradeamento dos pequenos recortes contemporâneos, a autora passeou pelo período da ascensão cristã, do renascimento, do Brasil colônia e suas grandes festas, ou mesmo pela calmaria da vida no interior, pelas mazelas do sertão e, por fim, chegando a vida urbana, pela mutação das comunicações e transporte, pelas imigrações, pela industrialização, entre outras, que guardaram a experiência vivenciada do lazer. Contudo, chegando à experiência na vida urbana, demonstrou sua indignação com o modo de vida individualista que percebe, expressando seus argumentos nas palavras de Carlos Drummond de Andrade:

Drummond de Andrade tão bem exprimiria: no cimento, nem traço da pena dos homens. As famílias se fecham em células estanques. Entretanto há muito se acabaram os homens. Ficaram apenas tristes moradores (Andrade apud Medeiros, 1975, p.30).

A morte em vida expressa pelo poeta parece ser justamente o que atravessa Medeiros e a move na elaboração do projeto de lazer e na constituição desse 
como um hábito social essencial ao ambiente público. Essa mutação da maneira de ver a vida em coabitação com os pares engendra o que a autora denomina de "novos estilos de vida" (Medeiros, 1975, p.79). Esses, abordam também a atividade criadora, os ritos mágicos e religiosos, como atividades culturais que promovem a personalidade coletiva dos indivíduos para a vivência em grupo. Esse apontamento é descrito como vantajoso ao meio social e, portanto, uma função que não se furta aos que administram.

O planejamento para o lazer se situa, portanto, na ordem da preocupação pública, em um tripé que envolve: a infraestrutura da cidade; a educação para a participação e a consciência das atividades recreativas como bem social e, por fim, a preparação de orientadores para o estímulo e a coordenação de tais práticas. Isso faz com que Medeiros afirme que "O estudo do lazer como problema social deverá ser incluído nos cursos de formação de administradores, arquitetos, urbanistas, paisagistas e educadores" (1975, p.122).

Assim, expressa que apenas com o "reverso do avanço" (1975, p.93) seria possível a constituição de formas de viver com maior liberdade, dado que o trabalho tem forte influência no cotidiano da sociedade, demonstrando o lazer como "esperança de reencontro do homem" (1975, p.94). Por tais afirmações, o desafio do lazer, é apontado como essencial pois, para a autora, "as atividades que então abraça não se prendem a motivos utilitários, mas se caracterizam pela alegria da própria execução, elas representam oportunidade única de dar largas ao espírito criador" (Medeiros, 1975, p.116).

Contrapondo sua visão à realidade apresentada, não é difícil notar que Medeiros defendeu a recreação organizada como alternativa ao desafio necessário do lazer, ciente das dificuldades da implementação de estruturas para tais práticas nos países em desenvolvimento. Entretanto, não abdica da arte tomada como aspecto fundamental, citando o parecer 331/1964 do Conselho Federal de Educação:

Como processo humano, por excelência, a recreação segue os caminhos da arte, e não da ciência. Os últimos tempos marcam três momentos sucessivos: o da ciência, o da técnica e, novamente, o da arte. Esta é chamada a exercer papel de relevo no programa educacional, tal como em certos períodos da história da humanidade exerceu missão preponderante. O futuro convocará a arte, cada vez mais, para que o homem não seja desumanizado (Medeiros,1975, p.221).

A temática do lazer e suas referências constantes à arte e aos aspectos da vida saudável marcam sua publicação. Suas inferências apresentaram possibilidades de recreação em vários espaços urbanos, com destaque para o projeto 
com diretrizes para implementação de um grande parque referencial no aterro do Flamengo - Rio de Janeiro, antigo Estado da Guanabara. Em todos os momentos, a prática do lazer como maneira de viver, com suas especificidades culturais e locais, são o foco de suas investigações; justificando, assim, seu projeto e argumentando pela necessidade de instalação não apenas no aterro do Flamengo, mas enfatizando a expansão das ações em território nacional, visto que para a pesquisadora, trata-se da preservação da saúde pública em termos mais amplos.

\subsubsection{Fela Moscovici: experiências sensíveis na formação}

A autora de "Laboratório de sensibilidade: um estudo exploratório" (1965) trabalha com dinâmicas de grupo, nas quais privilegia as relações humanas, pois entende que "a sensibilidade social consiste na capacidade de perceber como os outros pensam, sentem e tendem a agir, concomitantemente à própria atuação" (Moscovici,1965, p. 12). O nome "laboratório" expressa a característica essencial do treinamento que, para a pesquisadora, é "propiciar ambiente para despertar e desenvolver processos de grupo, favorável à descoberta, ao reconhecimento, à análise[...] comunicações livres e frequentes são estimuladas, bem como comentários sobre o que vêem, ouvem e sentem" (Moscovici,1965, p. 12).

Desta maneira, o grupo promove uma situação de aprendizagem, permitindo comportamentos exploratórios e tentativas para familiarizar-se com novas ideias e sentimentos, partindo do princípio que "aprender a viver com os outros é uma das mais complexas e vitais aprendizagens a realizar" (Moscovici,1965, p.14). A autora justifica suas ações na experiência preparatória da educação, pois afirma que "ao administrador cabe a tarefa, gloriosa e ingrata, de, conhecendo os fatos, as alternativas e as consequências, tomar as decisões e agir" (Moscovici,1965, p. 12), contrapondo lideranças entre os participantes: democrática e autocrática em seu grupo "T", de treinamento de sensibilidades. Esse objetivo de treinamento experiencial, dos que se propõem a serem líderes, envolve a presença em laboratório que oferece estímulos sensíveis, tratando de gerar e de buscar alternativas de ação em tais situações.

A intenção de multiplicar as práticas experienciais sensíveis se dá na descrição dos treinamentos em diversos lugares do Brasil, com seu registro de atuação que embasam ao final, na conclusão, apontamentos a pontos fracos, tais como falta de previsão do número de participantes, frequência irregular, e a pontos fortes, como a didática diferenciada, experiências práticas e o conhecimento de si e dos outros. Nesse contexto, utiliza a escuta para aferir a apreciação geral que aponta 
como satisfatória, por se tratar de um estudo exploratório, enfatizando uma temática esporádica nos estudos administrativos: a sensibilidade na relação com o outro.

Portanto, não há trabalho de competição (Moscovici, 1965, p.53), mas o conhecimento do ambiente de origem de cada participante para compreender suas necessidades (Moscovici,1965, p.42) e, desta maneira, chegar a desenvolver o que a pesquisadora denomina de "aprender a aprender" (Moscovici,1965, p.35), espaço em que cada participante estimulado se torna analista de seus próprios processos de aprendizagem.

Foram dois laboratórios realizados na Escola Brasileira de Administração Pública, dos quais houveram registros efetuados pela pesquisadora, diante do relato dos educandos e dos orientadores que efetivaram a prática. O sistema de avaliação adotado inicia sempre pelo julgamento do próprio indivíduo, submetido a treinamento de sensibilidade. Processo em que o educando pode julgar do progresso que pensa e que sente ter realizado, na compreensão de sua conduta e da conduta alheia e na aquisição de meios para convivência mais harmoniosa com os outros (Moscovici, 1965, p.81).

Nas mais variadas formas de expressar, alguns educandos optam por relatos orais, enquanto outros optam por relatos escritos, ocorrendo também de utilizarem o desenho como forma de expressão. Segue duas imagens dispostas no caderno EBAP (FIGURAS 1 e 2):

Figura 1 - Desenho elaborado pelos participantes do laboratório de sensibilidade

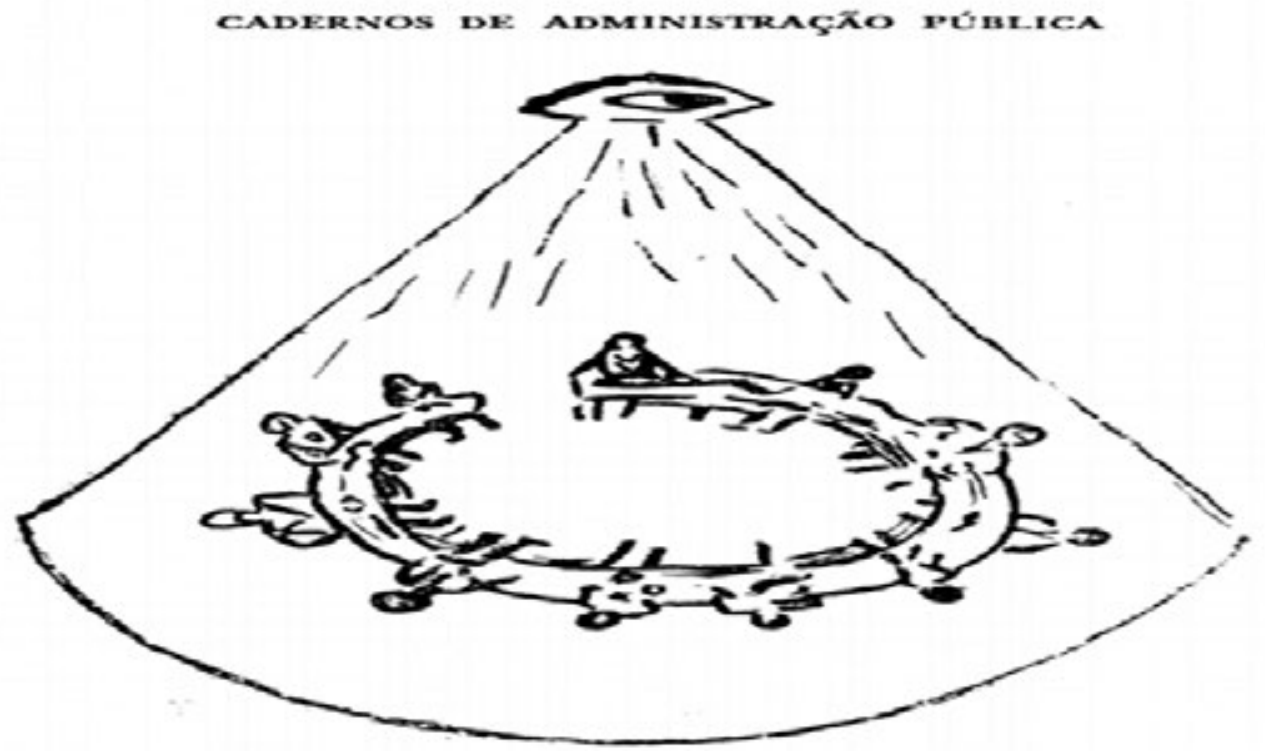

Fonte: Moscovici (1965, p. 104). 
Neste primeiro desenho escolhido, ainda que na pesquisa feita por Moscovici (1965) não haja um julgamento das percepções, é possível notar que o educando, ao ilustrar a conversa junto aos pares supervisionados por um olho superior, tende a percepção de menor liberdade do que a pesquisadora infere propiciar em suas abordagens. Da mesma maneira, há o contrário, como pode ser observado na próxima figura (FIGURA 2):

Figura 2 - Desenho elaborado pelos participantes do laboratório de sensibilidade

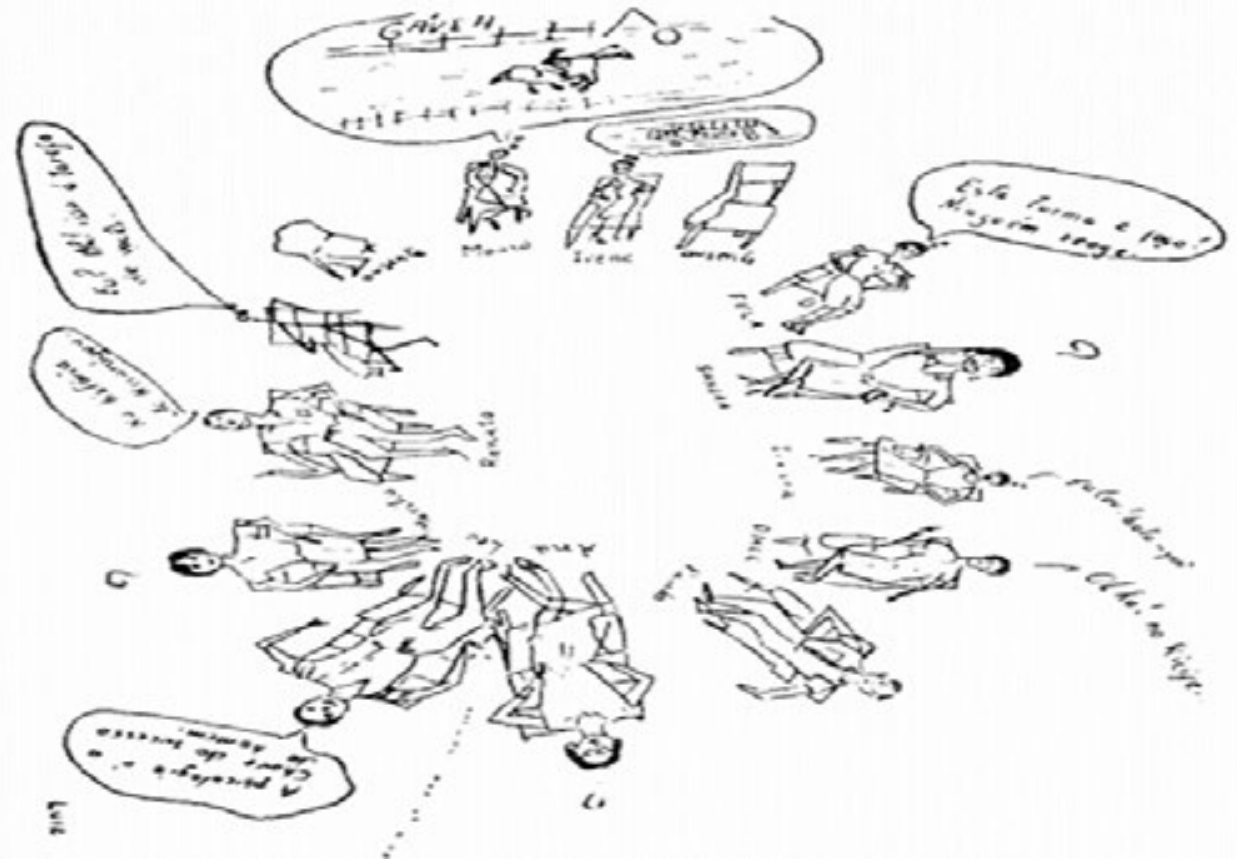

Fonte: Moscovici (1965, p. 102).

Nesta outra manifestação, a linguagem entre os pares é evidente, e na visão do educando, a pesquisadora se insere na ação realizada, proferindo: "Esta turma é fogo! Ninguém reage" (Moscovici, 1965, p.127), denotando sua participação ativa no incentivo aos alunos. Nessa participação coletiva, na avaliação geral, segundo a pesquisadora, os participantes concluíram que o laboratório proporcionou elementos, dos quais só tiveram consciência mais tarde, e que as experiências neste convívio serviram para ampliar e desenvolver sua compreensão no terreno das relações humanas.

A ação do laboratório diante do desafio permanente de reduzir os conflitos, e melhorar o entendimento entre as pessoas, é o de buscar desenvolver a habilidade de cada um lidar com os outros, liderando e sendo liderado. Espaço esse 
em que a autora conclui que "seria imprudente formular conclusões definitivas [...] o problema permanece em aberto" (Moscovici,1965, p.152).

\subsubsection{Ruth Scheeffer: habilidades artísticas em testes psicológicos}

Autora de "Introdução aos testes psicológicos" (1962;1968), Ruth Scheeffer, busca estabelecer testes sobre aptidões: mentais, intelectuais, artísticas, psicomotoras, de personalidade, de expressões e de interesses. Através deles, são elaboradas sínteses de cada área que considera essencial o desenvolvimento das aptidões dos administradores públicos. Entre tais testes psicológicos, a autora insere o teste de aptidões artísticas, inferindo que "no terreno das Artes, a verificação das habilidades e aptidões é de suma importância" (Scheeffer,1968, p.64).

Ao dividir em fatores, a autora mensura aspectos de habilidade manual, de perseverança, de experiências sensoriais e perceptivas e de fatores emocionais e motivacionais. Tais elementos tomados como fatores que seriam de importância aos educandos da EBAP apontam para uma parcela da formação pouco abordada na formação dos profissionais, pois, para a autora, a finalidade dos testes artísticos seria: "para localizar os estudantes e indivíduos que possuam talento artístico" (1968, p.70).

Os testes artísticos, ainda que elencados em um pequeno fragmento do compêndio de testes psicológicos, demonstram a visão para existência de uma área artística, a ser explorada entre os educandos da EBAP. Segundo a pesquisadora, "os mais divulgados testes artísticos se referem aos dois ramos da Arte: "os de Artes Plásticas e os Musicais" (Scheeffer,1968, p.64). Entretanto, um item em particular chamou a atenção: a inferência da "Imaginação criadora" como uma "habilidade de organizar impressões vividas sensoriais para a estruturação de uma obra de arte" (Scheeffer, 1968, p.65).

É preciso esclarecer que não foi encontrado registro de aplicação desses testes artísticos entre os educandos da EBAP, entretanto, a possibilidade aberta dessa abordagem é um fator diferenciado. Ao final da explanação, Scheeffer (1968) não elabora uma conclusão sobre os testes, todavia, apresenta-os como necessários aos estudos administrativos e aponta para a ineficiência de tais estudos para processos de seleção.

3.2.8 Catheryn Seckler-Hudson: escrita que salpica literatura

Autora de "Principais processos de organização e direção" (1955), Catheryn 
Seckler-Hudson foi uma norte-americana que teve seus escritos traduzidos pela EBAP. Seu trabalho apontava critérios e recomendações para a administração. Durante sua explanação sobre planejamento, foi rigorosamente restrita aos aspectos científicos e citações. O que chama a atenção são as inserções entre as páginas dos capítulos; primeiro cita Nabuco:

Tenho diante de mim um caderno de 1869, em que copiava as páginas que em minhas leituras mais me feriam a imaginação, método de educar o espírito, de adquirir a forma do estilo, que eu recomendaria, se tivesse autoridade, aos que se destinam a escrever, porque, é preciso fazer esta observação, ninguém escreve nunca senão com o seu período, a sua medida, Renan diria a sua arritmia, dos vinte e um anos (Nabuco apud Seckler-Hudson, 1955, p.28).

Em uma ação ao mesmo tempo reflexiva e educativa, destoando um pouco com a temática abordada de planejamento e suas fases, entretanto, fortemente condizente com a atividade de pesquisadora, Seckler-Hudson é sábia ao se expressar de maneira sutil no espaço de sua pesquisa. Aspectos da elaboração literária, passando pela imaginação, espírito, estilo e período, são enfatizados. A escolha das citações que reverenciam a atividade intelectual do pesquisador, especificamente por práticas de leitura e de escrita, é expressa também nesta outra citação:

Cada operação diferente na leitura exige um novo passo no pensamento, e, assim, as notas feitas nos vários estágios deste processo exprimem a variedade de atos intelectuais realizados. Se uma pessoa procura aprender a estrutura de um livro, pode fazer várias tentativas de resumo de suas partes principais, antes de contentar-se com a apreensão do todo. Resumos esquemáticos e diagramas de todos os tipos são úteis para separar os pontos principais dos secundários ou tangenciais. Quem pode e quer marcar um livro deve sublinhar as palavras e sentenças importantes, à medida em que forem surgindo. Mais do que isso, deve anotar as mudanças de significado, enumerando as páginas em que as palavras importantes são usadas, sucessivamente, em sentidos diferentes. Se o autor parece contradizer-se, deve fazer-se alguma anotação nos lugares em que essas inconsequências ocorrem, marcando o contexto para possíveis indicações de ser a contradição apenas aparente (Mortimer apud Seckler-Hudson, 1955, p.16).

É possível notar uma relação de prática de estudo, ao mesmo tempo que é possível estabelecer a expressão de relações mais íntimas, de uma certa identidade com as citações, observe:

Há pessoas que gostam de anotar na capa ou nas últimas páginas do livro. Pensam, como eu, que isto evita o trabalho de uma leitura extra, para redescobrir os principais pontos que pretendiam guardar. Vocês custarão mais a emprestar seus livros, se os 
anotarem ou se escreverem em suas últimas páginas. "Eles se tornarão documentos de sua autobiografia intelectual e vocês não gostarão de confiá-los a ninguém, exceto ao melhor dos amigos." (Mortimer apud Seckler-Hudson, 1955, p.25).

O recurso da ênfase nos aspectos considerados de "menor rigor" científico que aparecem entre as páginas expõe essa relação autobiográfica, e até de convivência, com os livros e os amigos. Ao passo que na última inferência a pesquisadora escolhe uma citação que explana aspectos da individualidade com a própria memória e o recurso que utiliza:

Acho mais eficiente não sobrecarregar minha memória enquanto leio e utilizar as margens do livro ou um pedaço de papel. O trabalho da memória pode e deve ser feito mais tarde. Mas penso que é melhor não deixar que ele interfira com o trabalho de compreender, que constitui o momento principal da leitura. Se vocês são como eu - e não como os que conseguem ler e gravar, ao mesmo tempo - podem afirmar se leram ativamente, pelo seu lápis ou papel (Mortimer apud Seckler-Hudson, 1955, p.31).

Lápis, papel e anotações para curar a memória? Ou apenas recomendações didáticas planejadas de uma pesquisadora em planejamento? Em qualquer uma das situações, observar a perspicácia de prender o leitor pelo diferente e pelo sensível e a engenhosidade de, ao mesmo tempo, estar e não estar dentro da pesquisa, operada pela autora, é uma perspectiva interessante.

\subsubsection{Beatriz M de Souza Wahrlich: traços da fenomenologia}

A autora de "Análise das teorias de organização" (1958; 1969; 1971; 1977; 1986), Beatriz M. de Souza Wahrlich, elaborou essa publicação, com cinco edições brasileiras, como tese de sua graduação em Administração Pública e Ciências Sociais pela Universidade de Nova York. Em seu estudo, aborda a necessidade de organização teórica na administração, pois logo de início explana:

\footnotetext{
A teoria administrativa pode não se ter ainda desenvolvido plenamente, pode estar mesmo na sua infância, e é certo não ter atingido a velhice. Talvez meu pensamento seja apenas determinado pelo desejo de que seja esta a verdade, mas, a meu ver, a teoria administrativa representa o setor mais original e vigoroso da teoria política americana contemporânea (Wahrlich, 1977, p.1).
}

Esse apreço pela teoria administrativa e pela prática da administração é perceptível em toda a tese da autora, que compreende a teoria das organizações 
de maneira múltipla pois, para ela, "hoje a abordagem desse campo de estudos é multi e interdisciplinar, e suas fronteiras cada vez mais largas" (Wahrlich, 1977, p.157), aspecto que vai demonstrando em sua abordagem ampla, tendo elementos práticos, instrucionais e filosóficos.

Em um tópico essencialmente filosófico, a pesquisadora, inserindo elementos de compreensão da fenomenologia, traz diversos autores que compreendem a teoria das organizações como uma realidade criada que pode conter diferentes significados conforme pessoas, culturas e processos envolvidos. Isso a faz concluir que a fenomenologia e os métodos quantitativos são, ao progresso das teorias de organização, elementos extremamente relevantes, importando mesmo num desafio frontal ao cientificismo quantitativo (Wahrlich, 1977, p.185).

Justificando seu argumento, ancorada em diversos autores, Wahrlich, ao final, expressa que:

[...] sentia que os cientistas sociais puderam escolher usar concepções logicamente controladas e não-ambíguas, que, por isso, estão mais afastadas da realidade histórica, ou usar conceitos menos precisos, mais ligados ao mundo empírico" (Wahrlich, 1977, p.160).

Essa possibilidade de escolha realizada pelos cientistas sociais, para as teorias organizacionais, apresentava-se com menor ênfase, e, em última análise, a pesquisadora infere:

[...] não resta dúvida de que a contribuição do enfoque do comportamentalista às teorias organizacionais, quando expresso quantitativa e não qualitativamente como geralmente acontece - sofreu um severo impacto negativo da crítica fenomenológica e, a seguir, da dos proponentes da metodologia qualitativa (Wahrlich, 1977, p.212).

Em alguma medida, sua expressão demonstra o quanto a fenomenologia e a pesquisa qualitativa abalaram o campo e agremiaram estudiosos desses aspectos. Todavia, Wahrlich faz apenas essa pequena passagem em seu escrito, sem um posicionamento mais demarcado, entretanto, na predominância do trabalho, as fontes que utilizam métodos que a pesquisadora denomina de "mais controlados" permeiam toda sua narrativa.

\subsubsection{Riva Bauzer: a implantação da EBAP}

Riva Bauzer foi a escritora que mais publicou sobre a temática da educação em Administração Pública, com três publicações e uma série bastante rica para a 
análise das diferenciações de abordagens que, em sua sutileza, se distanciavam do discurso mais ratificado da época. Em suas pesquisas há marcas expressivas de contraste com a metodologia e saberes importados de outras nações, demonstrando uma frequente preocupação com a elaboração de ações locais.

Talvez seja esse o panorama apresentado como possível por Riva Bauzer. A inserção da narrativa por outros caminhos, nesses locais de subjetividades que se transformam constantemente. Ela, ainda, acrescenta o diálogo com as imagens e os discursos discentes, que se contrapõe ao ideário progressista predominante, abrindo a possibilidade de observar muitas das lutas que se mantém em voz mais baixa dentro do espaço, em suas sedimentações, como as apresentadas por Bauzer (1965, p. 13).:

A própria palavra ciência é frequentemente aplicada a um conjunto organizado ou sistematizado de conhecimentos chamados objetivos, embora em realidade talvez fossem mais bem descritos como conhecimentos significativos, passíveis de verificação. Talvez, por isso, algumas pessoas menos avisadas acreditam que certos ramos do saber são científicos ao descreverem objetos ou coisas tangíveis, enquanto outros setores permanecem não-científicos ou a-científicos porque descrevem aspectos da realidade demais difícil ponderação ou avaliação. Na verdade, podemos dizer que existe, em determinados campos do saber, maior certeza científica que em outros.

A partir dos signos dispostos à ciência, Bauzer descreve que também é possível percorrer campos de menor ratificação social, abrindo os ramos do saber a uma produção de memória a partir da instituição, de seu corpo presente, de suas publicações, mas também da prática dos educandos, dos acessos dos corpos, dos sucessos e insucessos e, principalmente, na identificação das dificuldades que a turma acompanhada apresentou. Em suas três publicações, a introdução engendrava a perspectiva das pesquisas que privilegiava a experiência brasileira:

O objetivo desse programa é o enriquecimento de nossa bibliografia especializada, com trabalhos que espelhem a experiência brasileira e encerrem a reflexão dos estudiosos de nossa problemática administrativa [...] A Escola Brasileira de Administração Pública, ao acrescentar esta série ao já volumoso caudal de publicações da Fundação Getúlio Vargas sobre o tema, o faz com especial prazer, por se tratar de trabalhos inteiramente voltados para nossa realidade, destinados a contribuir para a elaboração de uma doutrina e o desenvolvimento de uma literatura genuinamente brasileira no campo da administração pública. [...] A pesquisa começará assim, dentro de casa (Bauzer, 1965, p.3; 1966, p.3). 
Com uma trilogia que registra experiências brasileiras defronte ao processo de transferência de saberes administrativos, ainda que não aponte essa perspectiva abertamente, a autora deixa evidente o tensionamento promovido pela ausência, na literatura brasileira, de material didático acerca da Administração Pública. O maior direcionamento de esforços para a importação de conhecimentos também é algo que frequentemente é contraposto pela educadora, que enfatiza as poucas referências à produção dos saberes locais.

Desta maneira, Bauzer é uma das narrativas que mais expõe a desconexão dos saberes importados com as práticas brasileiras. Tais enunciados, ao longo das publicações de Bauzer, vão sendo descritos em maior ou menor grau, porém, estende-se à toda investigação publicada, formando seu ponto característico.

\section{CONSIDERAÇÕES FINAIS}

Conhecer o território da formação do administrador público, a estruturação da educação em torno desse saber, demarcar o ratificado e encontrar o sorriso feminino entre as lacunas foi o resultado que se explanou por meio desse recorte das narrativas. Em uma análise que verificou as temáticas abordadas e a forma de expressão das autoras, foi possível estabelecer alguns pontos de diferenciação e, também, de similaridade.

Nessa contextualização pontual, as abordagens de aspectos de lazer, de descrição de práticas vivenciadas em estágios estudantis, de acompanhamentos de períodos dos alunos no curso, de registro de percepções de falas, tanto dos educadores quanto dos estudantes, são expressões que não predominaram a ótica masculina. Em contraponto, na narrativa feminina não foi incomum encontrar análises do cotidiano, das experiências e das práticas de escuta, o que é pouco usual nos discursos masculinos, tanto em sua temática quanto em sua forma de explanação, que frequentemente se evidenciaram dentro das análises de gastos, de procedimentos de gestão, de contas e de orçamentos.

Outro ponto sobressalente é que a escrita feminina se mostra mais plural e com saberes menos matizados pelo discurso que advém de outras nações - os saberes importados que fortemente influenciaram esse período histórico da administração pública em implantação no contexto brasileiro -, concebendo palavras locais, frases ditas "não acadêmicas", citações literárias, ou mesmo registrando as falas dos educandos como aspectos de valor ao pensamento e a estrutura do saber em formação - práticas que, talvez, ainda não tenham se estendido à maneira pela qual se inserem os discursos da área em tempos hodiernos. Fruto 
dessa pequena evidência, há o efeito de demonstrar como práticas educativas que não se constituem nas mais difundas, são da ordem do cotidiano real e possível. Agora. Tanto quanto foram necessárias e produziram seus efeitos ao longo do período histórico analisado.

Em outra ponta, evidenciar na história mulheres que narram pode ser um abalo na reflexão, ao revisitar as verdades estabelecidas em tempos e espaços específicos. Isso leva a especular que se a história fosse recontada por mulheres, crianças, idosos - entre tantos ou nenhum perfil -, que não predominantemente pelo discurso do sujeito universal, ela deslocaria as mais diversas práticas na atualidade. Portanto, resta ainda, talvez, um inefável sabor na perspectivação de saberes que não se furtam às múltiplas vozes do passado-presente reescrito: elas parecem ofertar a condição de possibilidade para existências menos castradoras e segregantes do que as que não cessamos de produzir ao longo das épocas.

\section{REFERÊNCIAS}

Almeida, Ângela Maria Vinagre de. (1970). Instrução programada: teoria e prática. Fundação Getúlio Vargas, Serviço de Publicações. Cadernos de Administração Pública. Recuperado de http://bibliotecadigital.fgv.br/dspace/bitstream/ handle/10438/12419/000020279.pdf?sequence=1\&isAllowed=y.

Bauzer, Riva. (1965). Formação para a administração pública: seleção de candidatos ao curso superior de graduação da EBAP. Fundação Getúlio Vargas, Serviço de Publicações. Cadernos de Administração Pública, 77(56). Recuperado de https://bibliotecadigital.fgv.br/dspace/handle/10438/13301?show=full.

Brasileiro, Ana Maria. (1968). O assessoramento legislativo. Fundação Getúlio Vargas, Serviço de Publicações. Cadernos de Administração Pública, (77). Recuperado de http://bibliotecadigital.fgv.br/dspace/bitstream/handle/10438/12419/000020279.pdf? sequence=1\&isAllowed=y.

Gomes, Maria Pia Duarte. (1965). Processo Decisório. Fundação Getúlio Vargas, Serviço de Publicações. Cadernos de Administração Pública. Recuperado de https://bibliotecadigital.fgv.br/dspace/handle/10438/11890/ browse?type=author\&value=Gomes\%2C+Maria+Pia+Duarte.

Machado, Marina Brandão. (1970). Estágios de treinamento para estudantes de administração: a experiência da EPAB. In Cadernos de Administração Pública, Rio de Janeiro, (75). Recuperado de https://bibliotecadigital.fgv.br/dspace/ bitstream/handle/10438/12417/000041969. pdf?sequence=1\&isAllowed=y. 
Medeiros, Ethel Bauzer. (1971). O lazer no planejamento urbano. In Cadernos de Administração Pública, (82). Recuperado de http://bibliotecadigital.fgv.br/dspace/bitstream/handle/10438/12419/000020279. pdf? sequence=1\&isAllowed=y.

Moscovici, Fela. (1965). Laboratório de sensibilidade: Um estudo exploratório. In Cadernos de Administração Pública, (59). Recuperado dehttp://bibliotecadigital.fgv.br/dspace/bitstream/handle/10438/12419/000020279. pdf?sequence=1\&isAllowed=y.

Scheefler, Ruth. (1968). Introdução aos testes psicológicos. In Cadernos de Administração Pública, (48). Recuperado de https://bibliotecadigital.fgv.br/dspace/bitstream/handle/10438/12003/48-2ed_000040714.pdf. Acesso em: 19 dez. 2019.

Seckler-Hudson, Catheryn. (1955). Principais processos de organização e direção. In Cadernos de Administração Pública, (1). Recuperado de http://bibliotecadigital.fgv.br/dspace/bitstream/handle/10438/12419/000020279. pdf? sequence=1\&isAllowed=y.

Wahrlich, Beatriz M de Souza. (1986). Uma análise das teorias de organização. In Cadernos de Administração Pública, (1). Recuperado de http://bibliotecadigital.fgv.br/dspace/bitstream/handle/10438/12419/000020279. pdf?sequence=1\&isAllowed=y.

Albuquerque Júnior, Durval Muniz de. (2019). O tecelão dos tempos: Novos ensaios de teoria da história. São Paulo: Intermeios.

Coelho, Fernando de Souza. (2019). História do ensino de administração pública no Brasil (1854-2006): Antecedentes, ciclos e a emergência do campo de públicas. Brasília: Enap.

Fischer, Tania. (1984). Administração pública como área de conhecimento e ensino: a trajetória brasileira. Revista de Administração de Empresas, 24(4), p. 278-288.

Foucault, Michel. (2014). Vigiar e punir: Nascimento da prisão. Petrópolis: Vozes.

Keinert, T. M. M. (1996). Análise das propostas dos cursos de administração pública no Brasil em função da evolução do campo de conhecimento. São Paulo: EAESP/ FGV-NPP.

Ricoeur, Paul. (2014). O si mesmo como outro. São Paulo: Martins Fontes. Veyne, Paul. (2008). Como se escreve a história. Lisboa: Edições 70. 